\title{
Molecular anatomy of neuronal interactions with special reference to the dopamine control of striatal functions
}

\author{
B. Bloch
}

Laboratoire d'Histologie-Embryologie, Unité Mixte de Recherches CNRS 5541 Interactions Neuronales et Comportements, Université V. Ségalen, 146 Rue Léo Saignat, 33076 Bordeaux Cedex France

\section{INTRODUCTION}

Modern neuroanatomy was initiated at the early beginning of the $\mathrm{XX}^{\text {th }}$ century when Cajal used the so-called silver impregnation technique to study the details of the anatomy of the nervous system. This technique, for the first time, permitted description and visualization of all components of neurons (Cajal, 1909). Thanks to this major methodological advance, Cajal and followers created microscopic neuroanatomy and gave detailed description of the structure of neurons and of neuronal circuitry in brain of animals and humans. During the following decades, numerous informations were obtained on the organization of the neuronal circuitry in all parts of the central and peripheral nervous system, in normal, experimental and pathological conditions. These works considerably helped to establish the modern anatomical basis of brain functions and dysfunctions. In the early sixties, the appearance of electron microscopy gave a new impulse to the understanding of brain and neuronal structures. For the first time, it permitted to visualise and describe unambiguously the structure of synapses and to have understanding of the internal organization of the neurons. In the same time, the development of biochemical approaches led to the discovery and characterization of several neurotransmitters, among which acetylcholine and monoamines. The improvements of biochemical and pharmacological approaches, the appearance of molecular biology led to the discovery of an unexpected number of new neurotransmitters. It also led to the discovery, the pharmacological and the biochemical characterization of neurotransmitter receptors. Cloning strategies allowed to have detailed knowledge of the structure of the neurotransmitters and of their receptors and demonstrated tremendous, unsuspected complexity of the molecules involved in neurotransmission. The neurotransmitter number is expected to be superior to two hundreds. The number of neurotransmitter receptors is considered to be over several thousands. Despite its importance for the understanding of neuronal interactions in normal and pathological conditions, classical microscopic neuroanatomy did not bring tools to establish links between anatomical organisation of neuronal circuits and the chemical substrates of neurotransmission and especially did not bring information on the localisation of neurotransmitters and receptors. 
In the early sixties, the seminal works of the Swedish histology school led to the appearance of the first techniques of so-called molecular neuroanatomy, or functional neuroanatomy that associated under the microscope the visualization of neuronal networks and of chemical components involved in neurotransmission. With the development of the so-called monoamine fluorescence histochemistry by Falck and Hillarp and colleagues (Falck et al., 1962; Carlsson et al., 1962), it was possible to describe for the first time chemically and anatomically identified neurons containing various monoamines. From this time, molecular anatomy has developed in many ways, taking advantage of the progress in immunological, pharmacological and molecular detection of neurotransmitters and receptors. Techniques have been refined, have improved, have been simplified with time. These especially include receptor radioautography, immunohistochemistry (IHC) and "in situ" hybridisation (ISH). Such techniques are now widely in use in all neuroscience laboratories and have allowed the rewriting of a new neuroanatomy associating description of neurons and circuits with their neurotransmitters and receptors. This revolution led also to reconsider deeply several concepts on the anatomical and cellular basis of neurotransmitter actions: in contrast to the prominent concept that production of certain neurotransmitters, especially neuropeptides were restricted to limited parts of the brain such as the hypothalamus, IHC and ISH have demonstrated that the largest part of neurotransmitters are widely produced throughout many parts of the central and peripheral nervous system and in other parts of the body such as the digestive tract, the lymphoid and the endocrine tissues. IHC and ISH also helped to demonstrate that, in many instances, a same neuronal system produces simultaneously several neurotransmitters, some of them of distinct chemical origin (Hokfelt et al. 1980 a,b; Hokfelt et al. 1994), some of them derived of a same precursor such as neuropeptides (Bloch et al., 1979; Bloch et al., 1986). It also demonstrated that a given neuronal population modifies the nature and the number of neurotransmitters it produces depending on neurochemical environment (Hokfelt et al., 1994). The histological detection of the receptors or of their mRNAs also demonstrated tremendous complexity in the localization of each receptor subtype depending on brain region and neuronal subpopulation. Immunoelectron microscopy appeared very useful to understand subcellular localisation of neurotransmitters and receptors. It especially helped to demonstrate that neurotransmitters are frequently released at distance of their target neurons and that neurotransmitter receptors are localized in many subterritories of the neuronal plasma membrane, frequently at extra synaptic sites, thus substantiating the demonstration that neurotransmitterreceptor interactions also involve non classical, non synaptic contacts (Agnati et al. 1995).

\section{DEVELOPMENT OF MOLECULAR NEURO- ANATOMY}

\section{Monoamine fluorescence histochemistry}

In the early sixties, the number of identified neurotransmitters was low and these molecules were difficult to detect by biochemical methods in brain extracts; these included acetylcholine, norepinephrine, epinephrine and other molecules considered as putative monoamine metabolites such as dopamine. The genial inspiration of Falck and Hillarp led them to adapt the fluorescent detection of monoamine derivates in fluids to their direct visualisation in brain tissue sections (Falck et al., 1962). They developed a sophisticated freeze-drying technique of tissues that preserved monoamines "in situ", inside the neurons that produce them. By using formaldehyde vapors, they transformed monoamines in green or yellow fluorescent derivates depending on their chemical nature. This led especially to the identification and mapping of the neurons producing dopamine, norepinephrine and serotonin. Not only all parts of the neurons containing monoamines could be identified, but it was possible to describe their number, their shape and their changes in experimental conditions and in diseases, such as Parkinson's disease. These seminal works were especially important for the understanding of the neurochemical basis of brainstem functions where several monoamine producing neurons are located, but also of other important brain 
areas such as the cerebral cortex and the hypothalamus (Carlsson et al., 1962). This was the beginning of a new era in neuroanatomy. The direct detection of monoamine producing neurons by histofluorescence was secondarily completed, then superspeeded by more simple, powerful and informative histological approaches such as the direct immunohistochemical detection of the monoamines (serotonin, norepinephrine) (Costa et al. 1982; Kohler and Steinbusch 1982) or their biosynthetic enzymes ( tyrosine hydroxylase, dopamine beta hydroxylase, (Hokfelt et al. 1975; Hokfelt et al. 1977; Hokfelt et al. 1980 a,b; Hokfelt et al. 1984), or such as the detection of mRNAs coding for these enzymes. Mononoamine histofluorescence will nevertheless remain as an historical landmark in neuroanatomy.

\section{Neurotransmitter IHC}

In the time monoamine established as neurotransmitters and were visualized as such in neurons, many other molecules known as putative neurotransmitters were identified by biochemical methods and secondarily through cloning techniques. Among them, are the neuropeptides, first of them identified in the early fifties inside the hypothalamus. These neuropeptides appeared as a growing class of neurotransmitters that were found not only in the hypothalamus, but also throughout the central and peripheral nervous system. In the meantime, independently, Coons developed immunofluorescence that allowed the direct detection of an antigenic molecule in tissue sections by using fluorescent antibodies (Coons 1971). Despite initial reluctancy, it appeared that a large number of neurotransmitters, could be detected by IHC (Barry et al., 1973, Steinbusch 1982; Hokfelt et al., 1984). This prompted a tremendous interest in all fields of neurosciences. Refinement of these techniques, improvements in sensitivity through signal amplification, use of non fluorescent markers such as peroxidase, gold particles and related molecules, and adaptation to electron microscopy opened a powerfull new area for histological detection of neurotransmitters. All neuronal systems producing neurotransmitters were then identified, mapped and described in details throughout all species. All neuropeptides appeared to be detectable through IHC. Neuronal systems producing so-called small neurotransmitters such as amino-acid derivates also became detectable through IHC detection of their enzyme for synthesis (Hokfelt et al. 1984): this includes tyrosine hydroxylase, choline acetyltransferase or glutamate decarboxylase. Some small neurotransmitters themselves such as glutamate, serotonin, or norepinephrine can be directly detected through IHC (Costa et al., 1982; Kohler and Steinbusch 1982). Development of double IHC, electron microscopic analysis deeply contributed to analyze modes of production of neurotransmitters.

\section{Receptor radioautography}

In the same time neurotransmitters were discovered and characterized in number, neurotransmitter receptors started to be purified and characterized thanks to the progress of biochemical and pharmacological techniques, but, in most instances, receptors were not available for a chemical or an immunological characterization. Despite these limitations, development of radioactive chemical ligands specific for a given receptor class became an efficient tool to identify, map and quantify neurotransmitter receptors in tissue sections in discrete brain areas (Chabot et al. 1996; Beaudet et al. 1998). Ligands (either agonists or antagonists) can be labelled with radioactive atoms and demonstrated all abilities to bind to receptors in tissue sections with appropriate pharmacological parameters. Such approach has nevertheless certain limitations: it does not differentiate between receptor isotypes for a same neurotransmitter. It has limited anatomical resolution and does not allow analysis at the single cell level. Despite this, receptor radioautography stands today as a widely used and a very efficient anatomical tool in neuropharmacology and neuroanatomy (Figure 1 C).

\section{In situ hybridization for neurotransmitters and receptors \\ Cloning of neuropeptide and of neurotransmit-} ter receptors opened up a new era in neurosciences and provided tools to study gene expression for neuroactive substances. In the early eighties, the development of ISH opened 

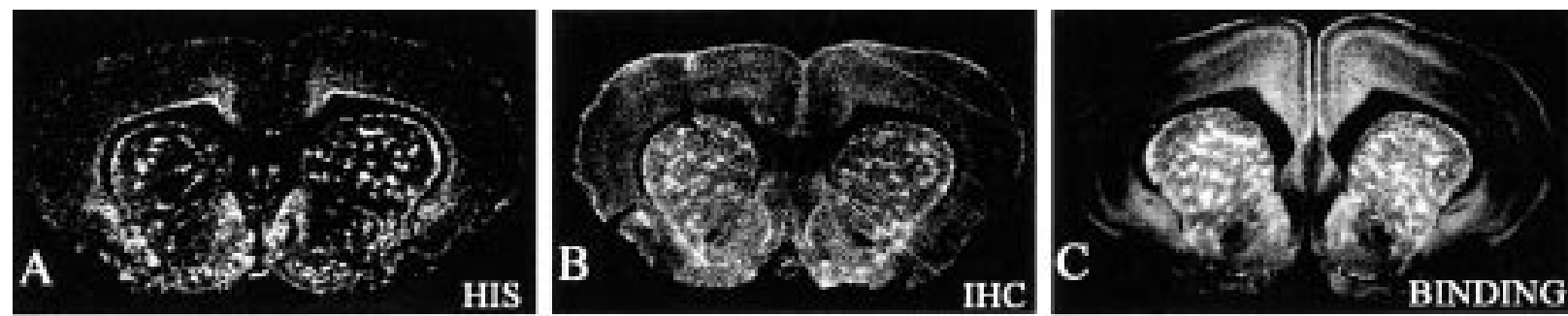

Fig. 1 - Histological detection of opiate receptor expression in the forebrain. Receptor expression can be detected by using three techniques that provide complementary informations: A, In situ hybridisation that detects mRNA for the receptor. B, immunohistochemistry that detect the immunoreactive receptor. $\mathrm{C}$, Binding with agonist that detects the receptor available for ligand binding. In the present figure, signal detection was obtained with radioactive probes. Labelled neurons display similar pattern of localisation in the forebrain. Negative prints of X-Ray film. From courtesy of C. Le Moine.

the possibility to localize, map and quantify mRNAs directly in tissue sections inside neurons. Since mRNA is prominently localized in neuronal cell bodies, ISH became a very efficient way to map the neurons expressing a given gene through identification of the mRNA in cell bodies (Bloch et al., 1986; Young et al., 1990). This appeared as a very powerfull technique to map the neurons producing neurotransmitters in addition to IHC (Figure 2). ISH also quickly appeared as an efficient technique to map the neurons producing neurotransmitter receptors, with exquisite anatomical and molecular resolution (Le Moine and Bloch, 1995, 1996) (Figure 2 and 5). Indeed, ISH allows to efficiently discriminate between mRNAs encoding very closely molecularly related receptors (Figure 5). This is especially very important to differentiate anatomically and neurochemically the neurons producing various receptor isotypes for a same neurotransmitter. With years, ISH refined many important technical aspects; this involved the development of non radioactive probes (Guitteny et al. 1988; Le Moine et al. 1995), improvements in sensitivity with cRNA probes that permitted the detection of genes expressed at a low level (Le Moine and Bloch, 1995), combined techniques, either double ISH or ISH combined with IHC (Normand and Bloch, 1991; Trembleau et al. 1993; Le Moine and Bloch, 1995) that appeared very useful to detect the simultaneous expression of several genes in a same brain area or in a same neuronal population (Figure 2 and 5). Radioactive probes appeared first very sensitive and efficient, but were progressively competed by non radioactive probes among which the digoxigenin labelled ones are very efficient (Le Moine and Bloch 1995; Le Moine et al. 1995). Quantitative ISH also developed and permits to measure mRNA variations at the single cell level (Young et al. 1986; Normand et al. 1988; Gerfen et al. 1990; Le Moine et al. 1994; Gerfen 2000b). It stands as a very efficient tool to analyse how neurochemical environment, especially when influenced by drug treatment modifies gene expression in neuronal subsets or anatomically defined areas (Figure 8).

\section{Receptor IHC}

Neurotransmitter receptors have been demonstrated to be expressed at the neuronal surface in cell bodies, dendrites and axons. Cloning of receptors allowed to produce antibodies against recombinant proteins or against synthetic peptides. While today, it is still difficult to obtain efficient antibodies for the identification of many receptors in tissue sections, IHC for receptors (Brown et al. 1995; Mantyh et al. 1995a; Mantyh et al. 1995b; Caillé et al., 1996) Bernard et al. 1998; Dumartin et al., 1998; Jansson et al. 1999) gave a new impulse to the understanding of production and localisation of neurotransmitter receptors in brain, through light and electron microscopy analysis (Figure 6 and 7). As compared to receptor radioautography, IHC provides exquisite molecular and cellular resolution. It is the only way to study the subcellular localisation of receptors. IHC especially helped to demonstrate that receptors have frequently extra-synaptic localisation and also have membrane localisation at the surface of the neurons that it is not directly related to the localisation and release of the corresponding 
neurotransmitter (Jansson et al. 1999). It also showed that the abundance and the subcellular localisation of the receptors, especially $\mathrm{G}$ protein coupled receptors is regulated by the neuro- chemical environment inside neurons (Mantyh et al. 1995a; Mantyh et al. 1995b; Bernard et al., 1998; Dumartin et al. 1998; Bernard et al., 1999; Bloch et al. 1999; Dumartin et al. 2000).
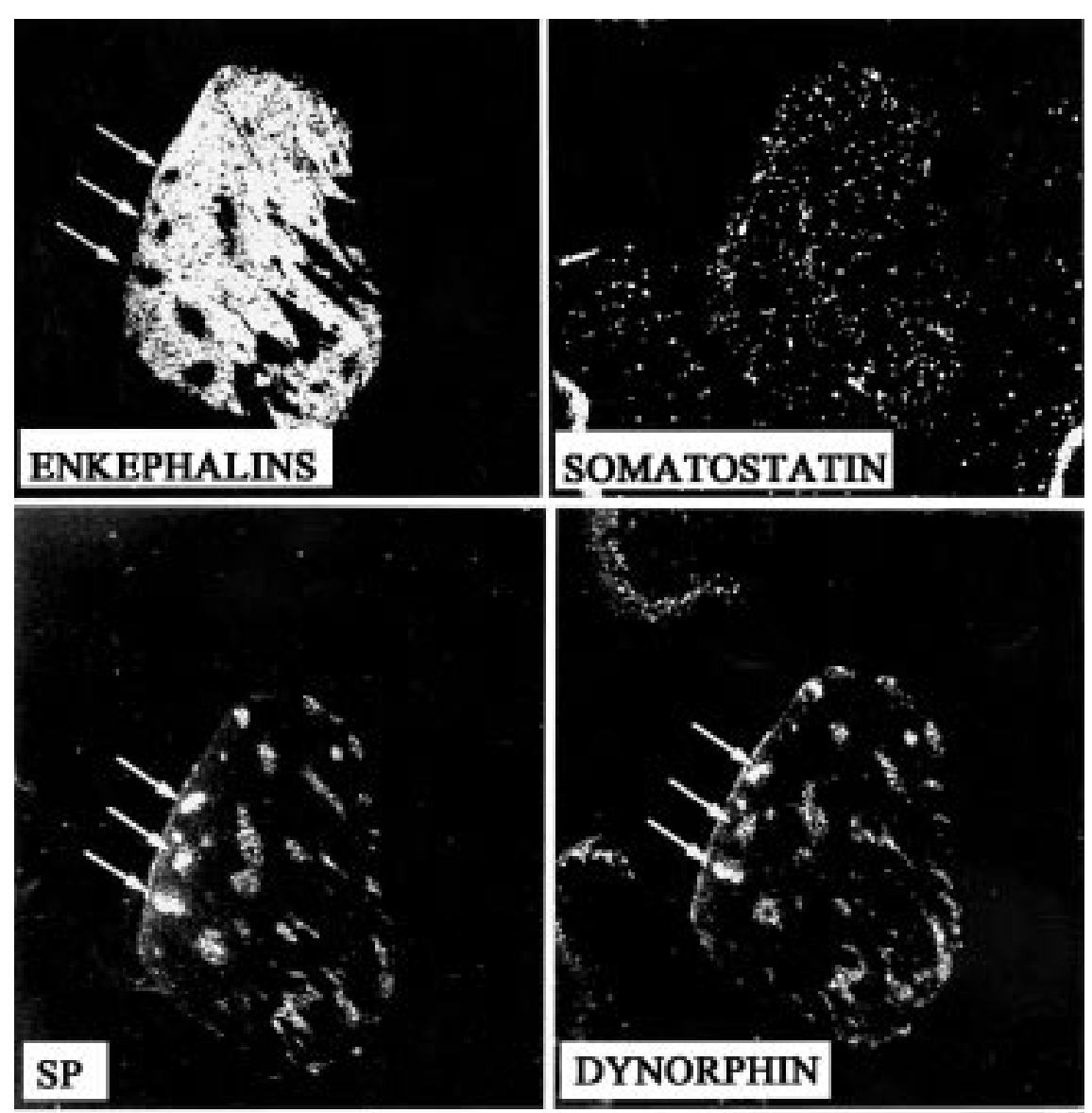

Fig. 2 - Detection of neuropeptide and dopamine receptor mRNAs in the human striatum (newborn). Upper pannnel: Neuropeptide mRNAs are detected with radioactive (S35) probes. Negative prints of X-ray films show distinct pattern of localisation according to mRNAs; Enkephalin mRNA is
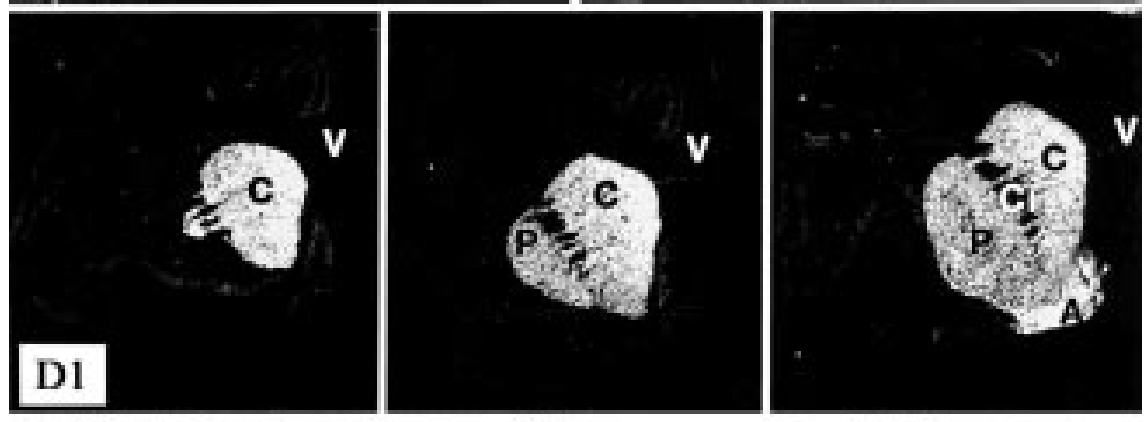
widely spread in the striatum. Somatostatin mRNA is present in scatterd neurons. SP and dynorphin mRNAs that have been demonstrated to be produced by same neurons display same pattern restricted to limited part of the striatum. This pattern is complementary from the one obtained for enkephalin mRNA. Lower pannel: ISH for D1 dopamine receptor shows expression throughout the striatum. Microautoradiographic analysis after double ISH with radioactive and non radioactive probes show that D1 and D2 are expressed by distinct neurons and that D1 receptor is expressed in SP neurons (From Aubert et al., 1999 D1 /D2 


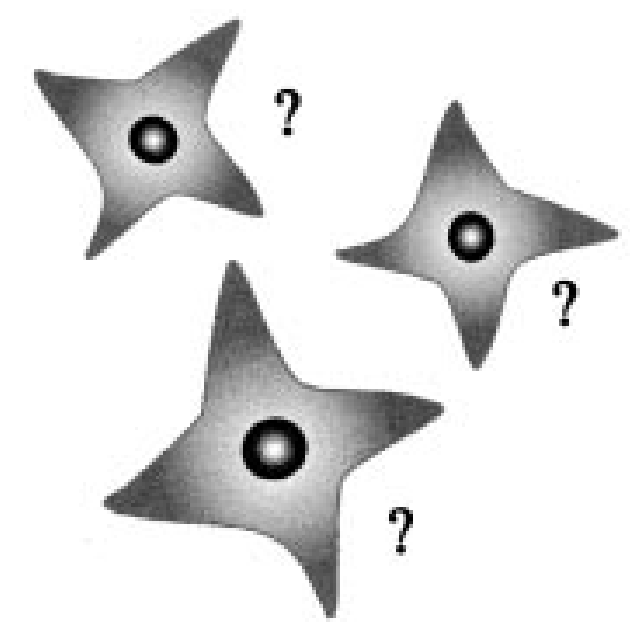

Neurotransmitters

Acetylcholine

GABA

Enkephalins

Substance P

Dynorphin

Somatostatin

NPY

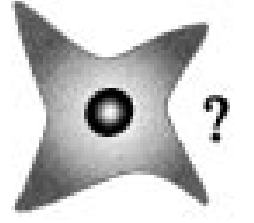

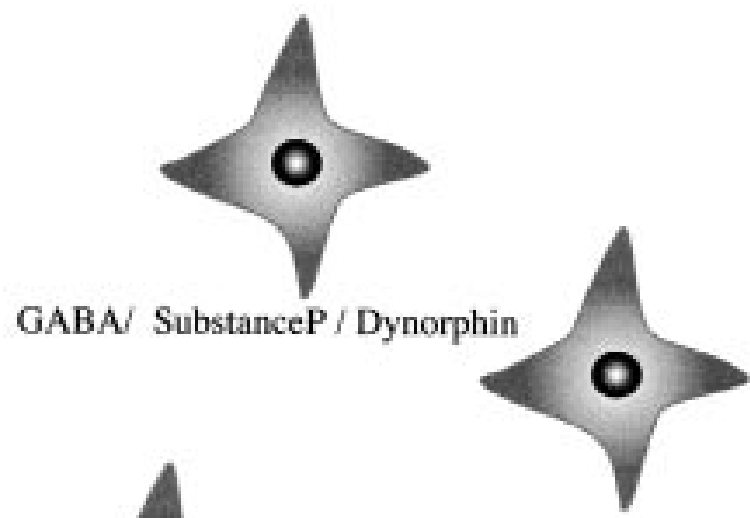

Somatostatin / NPY

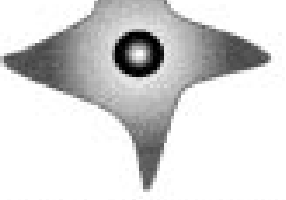

GABA/ Enkephalins

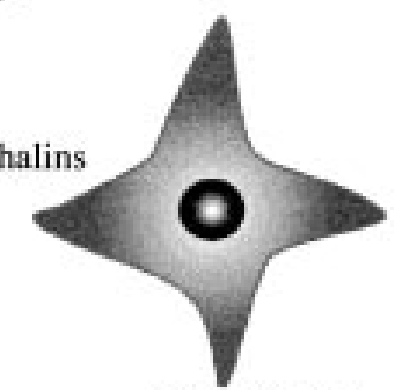

Acetylcholine

Fig. 3 - Striatal neurons neurotransmitter production. On the left, the main neurotransmittors known to be produced in the striatum and the four main neuronal population so far identified on the bais of classical histological analysis (Smith and Bolam, 1990). On the right, the results obtained by using IHC and ISH permit to associate each neurotransmitter with a neuronal subpopulation (See Kawagushi et al., 1995 for details).

FUNCTIONAL NEUROANATOMY OF BASAL GANGLIA WITH SPECIAL REFERENCE TO THE DOPAMINE CONTROL OF STRIATAL FUNCTIONS: PRESENT AND FUTURE

\section{INTRODUCTION}

Basal ganglia are key structures in several important central nervous system functions. In basal ganglia, the striatum (Smith and Bolam, 1990; Gerfen 1992a; Gerfen 1992b) has received special attention for several reasons: it is one of the main actor of basal ganglia functions and dysfunctions; its activity involves several important neurotransmitters, especially dopamine, glutamate, opioid peptides, GABA and acetylcholine (Kawaguchi et al. 1995); the striatum has been demonstrated to be involved in several diseases or disorders in humans, especially Parkinson's disease (Hirsch 2000), Huntington chorea, mood disorder and drug addiction. Striatal neurons are targets for many drugs that are important in human pathology, especially psychoactive substances, neuroleptics and opiates. The striatal organisation has been largely explored in animals and humans through classical neuroanatomy: the striatum is 

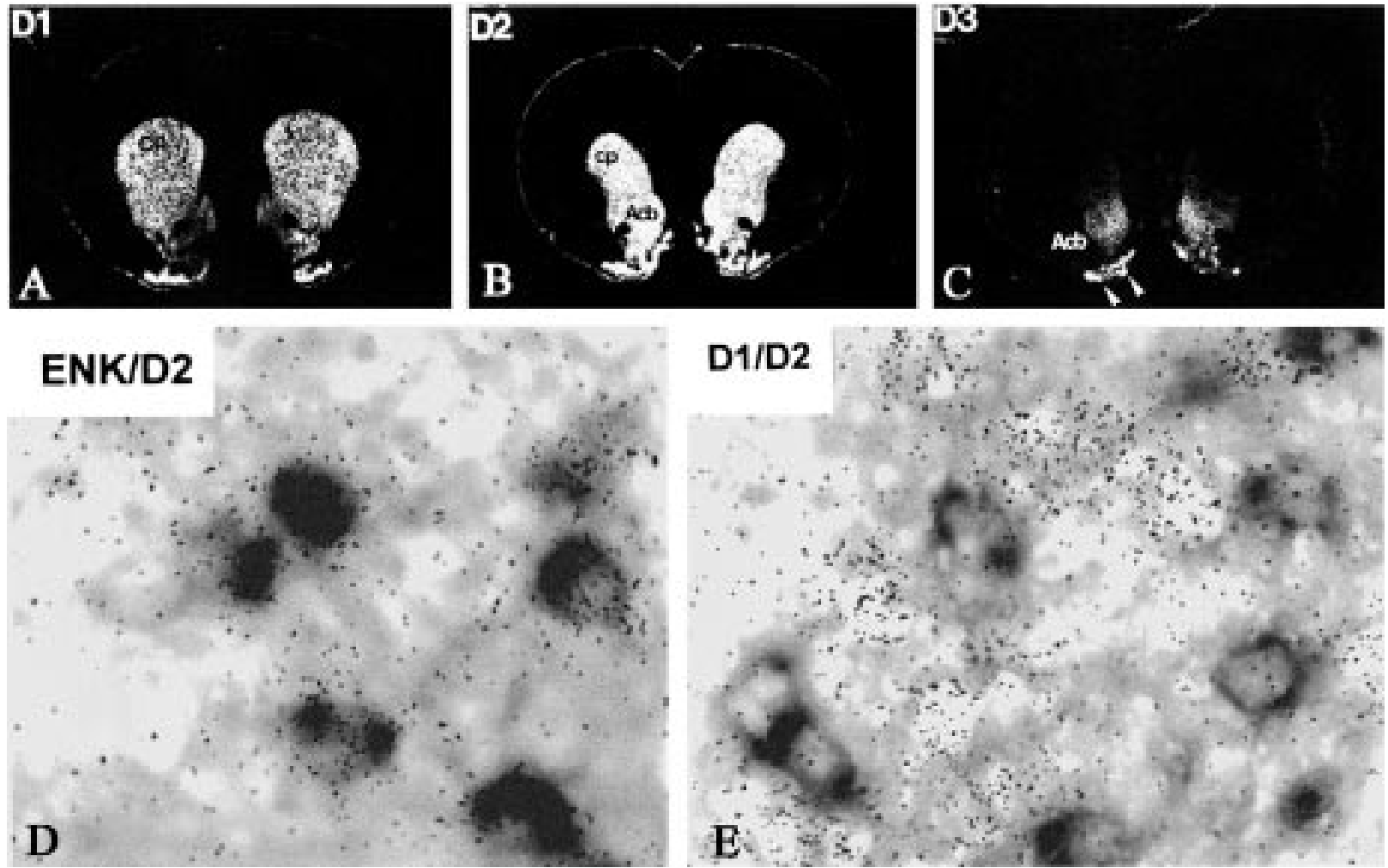

Fig. 4 - Detection of dopamine receptor mRNA in the rat striatum. A to C show detection of mRNAs for D1, D2 and D3 dopamine receptor in the rat forebrain (negative prints of X-Ray film after radioactive ISH). D1 and D2 are expressed throughout dorsal and ventral striatum while D3 receptor expression is restricted to the ventral striatum (Acb: accumbens nucleus). (C). D and E show double ISH with radioactive and non radioactive probes demonstrating that D2R is expressed by enkephalin neurons and that D1 and D2 are expressed by distinct neuronal subpopulations (from Le Moine and Bloch, 1995, 1996).

a subcortical structure that contains several neuronal subpopulations: most of them are socalled medium spiny neurons that project outside the striatum (Smith and Bolam 1990). A small part of these neurons are subpopulations of interneurons, some of them medium sized, the other large sized (Figure 3) (Kawaguchi et al. 1995). Anatomical analysis distinguish socalled dorsal striatum (caudate and putamen) that is considered to be involved in motor control, and the ventral striatum (accumbens nucleus, Calleja islands) that is considered to be more involved in mood and behavior control. The striatum receives many inputs according to complex anatomical organisation: dopamine inputs originating from the substantia nigra and ventral tegmental area are the most well known, but the striatum also receives important inputs from the cerebral cortex and the thalamus (Smith and Bolam, 1990; Gerfen 1992a). Mole- cular anatomy contributes efficiently to describe neurochemical organisation of the striatum. In order to illustrate the potential and efficiency and the future of molecular neuroanatomy in the understanding of neuronal basis of neurotransmitter action in the brain, we will consider the neurochemical organisation of striatal neurons and of their innervation by dopamine fibers.

Phenotypical characterization of striatal neurons A large variety of neurotransmitters has been identified inside the striatum that include GABA, enkephalins, SP, dynorphin, somatostatin, NPY, acetylcholine, and nitric oxyd (Figures 2 and 3). From the early eighties, the use of IHC and ISH has allowed to associate each neurotransmitter found in the striatum with each neuronal subpopulation. Double IHC, combination of IHC with HIS and double HIS was espe- 


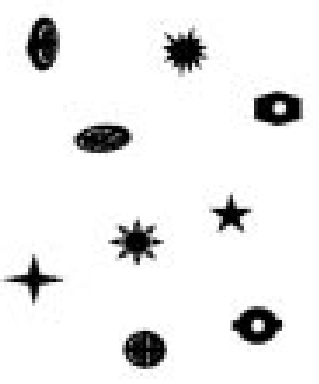

\section{Neurotransmitter receptors}

Dopamine receptors D1,D2,D5

\section{Muscarinic receptors $\mathrm{m} 1, \mathrm{~m} 2, \mathrm{~m} 4$}

\section{Adenosine receptors} A2A

\author{
Opioïd receptors \\ mu, delta
}

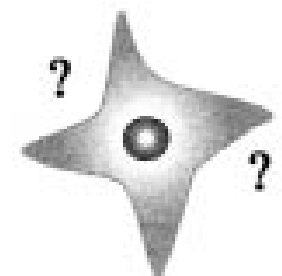

GABA/enkephalins

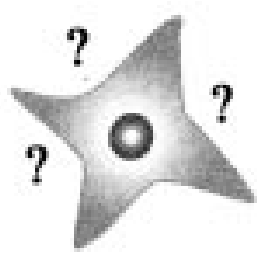

\section{GABA / SP / dynorphin}

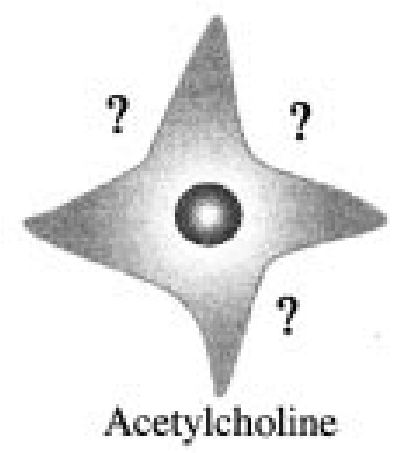

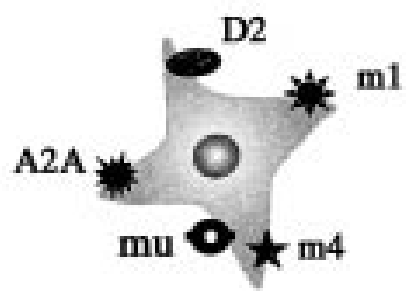

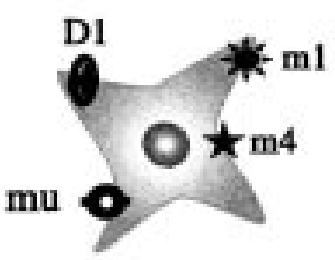

Fig. 5 - Striatal neuron receptor equipment. On the left, are represented various neurotransmitter receptor isotypes known to
be expressed in the striatum and three neuronal populations identified in the striatum. On the right, are summarized the results of the analysis performed with double ISH to associate each receptor isotype with one or several neuronal subpopulation (See Figure 2; Figure 4 D and E and Le Moine et al., 1990, 1991, 1995; Bernard et al., 1992; Georges et al., 1998; Svennningson et al., 1999).

cially critical to demontrate coproduction of several neurotransmitters by a same neuronal subpopulation (Kawaguchi et al. 1995; Brana et al. 1996) (Figs. 2 and 3). All output neurons produce GABA as demonstrated by glutamic acid decarboxylase IHC or HIS. These neurons coexpress neuropeptides, either enkephalin or substance $\mathrm{P}$ and dynorphin depending on their targets. Large sized interneurons have been shown to produce acetylcholine only. The other interneurons simultaneously produce somatostatin, NPY and nitric oxyde, and possibly GABA for some of them (Kawaguchi et al. 1995). Detailed studies demonstrated that stri- atal neuronal content slightly vary with striatal subterritories (striosome/matrix; dorsal/ventral striatum) and with phylogeny (rodents/primates) (Figure 2). Experimental analysis demontrated that neurotransmitter production by striatal neurons can be dramatically altered by neurochemical environment, and can change within very shorts periods of times: as an example, D1 stimulation or neuroleptic treatment induces neurotensin production in more than $50 \%$ of striatal neurons within a few hours (Schiffmann and Vanderhaeghen 1993; Castel et al.; 1994). Striatal denervation or neuroleptic treatment 
induces cholecystokinin production. (Schiffmann and Vanderhaeghen 1992; Schiffmann and Vanderhaeghen 1993; Castel et al., 1994). This illustrates that in experimental and pathological conditions, the nature of neurotransmit-

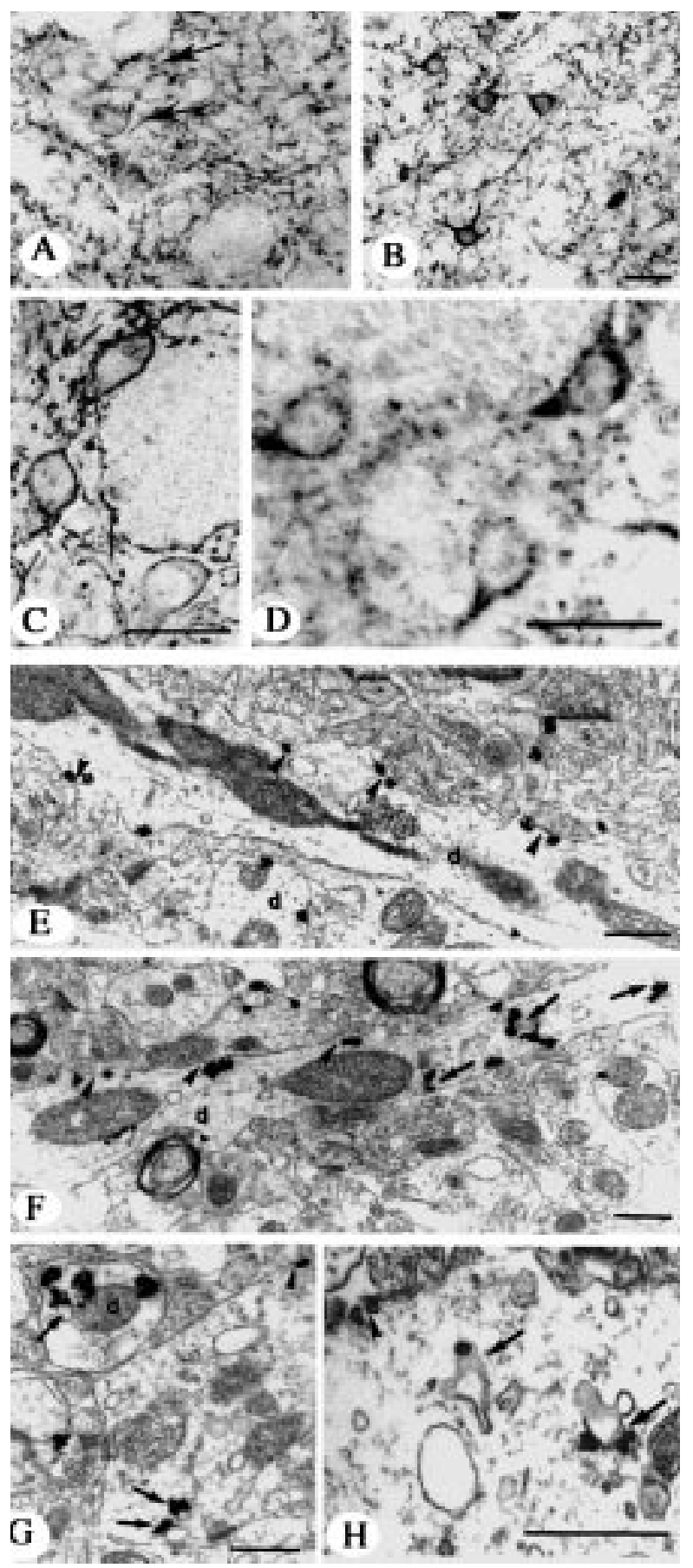

ters produced by striatal neurons can be modified and must be interpreted cautiously as compared with situations observed in the normal adult brain.

\section{Dopamine receptor equipment of striatal neu- rons}

Dopamine axons are widely spread throughout the striatum but establish few direct contacts with striatal neurons. Dopamine is mostly released at distance of the striatal dendrites and cell bodies. Striatal neurons are sensitive to dopamine through expression of $\mathrm{G}$ protein coupled receptors; two classes (D1 and D2 type) have been identified on the basis of molecular and pharmacological characteristics (adenylate cyclase coupling). Both classes are widely expressed by striatal neurons, as demonstrated by radioautography with specific ligands. Six receptor isotypes have been identified so far, encoded by five genes; Dopamine receptor gene expression by striatal neurons has been largely documented by ISH (Gerfen et al., 1990; Le Moine et al., 1990; Le Moine et al., 1991; Le Moine and Bloch, 1995; Brana et al., 1996; Le Moine, 1996; Aubert et al., 2000) (Fig. 4 and 5). D1 and D2 are widely expressed throughout dorsal and ventral striatum in rodents and humans. D3 expression is restricted to neurons of ventral striatum in rodents, but is also expressed throughout dorsal striatum in monkey and humans (Le Moine and Bloch, 1996 Ridray et al. 1998; Suzuki et al. 1998;Gurevich and Joyce, 1999). ISH at the microscopic level demonstrated that all neuronal populations express at least one dopamine receptor in the striatum. Identification of the neuronal

Fig. 6 - Immunohistological detection of D1R in striatal neurons in normal rats and after acute stimulation. D1R detection by immunohistochemistry at the light (A to D) and electron microscopic level in the rat striatum. A, C and E show D1R visualised in normal rat and located at the plasma membrane in cell bodies and dendrites. B, D and F show internalisation of the D1 receptor in the cytoplasm of the neurons after stimulation by amphetamine or direct dopamine agonist (SCH 98858). G and H show details of the localisation of D1R in the cytoplasm after stimulation demonstrating that $\mathrm{D} 1 \mathrm{R}$ is associated with endosomes in dendrites $(\mathrm{G})$ and cell bodies $(\mathrm{H})$ (From Dumartin et al., 1999). 

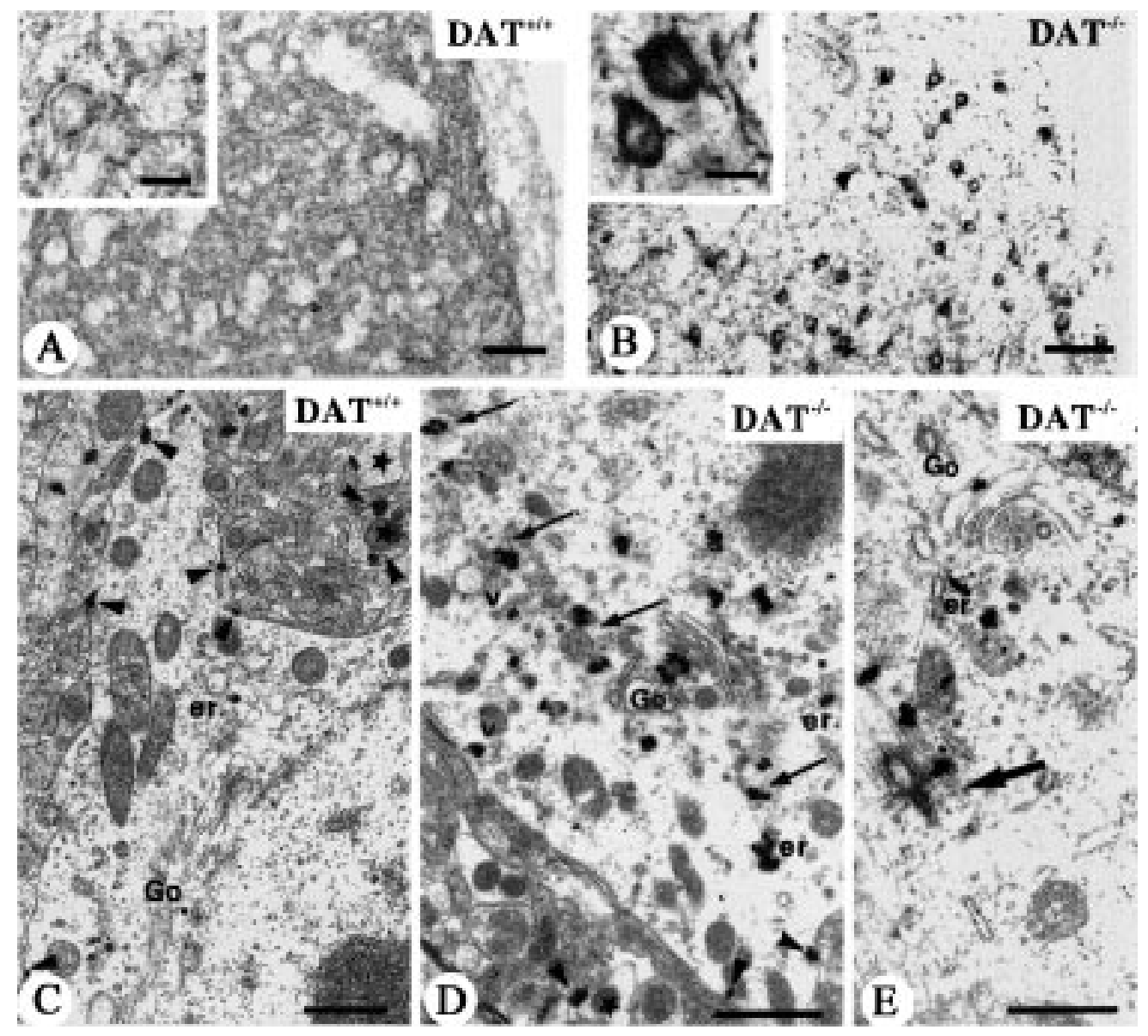

Fig. 7 - Immunohistological detection of D1R in striatal neurons in dopamine transporter deficient mice. D1R detection in normal mice (A and $\mathrm{C}$ ) and in mice having knock-out for dopamine transporter $(\mathrm{B}, \mathrm{D}, \mathrm{E})$ and consequently chronic elevated extracellular dopamine concentration. In normal mouse (A, C), the D1R is located at the plasma membrane. In transporter deficient mouse, there is a massive depletion of D1R at the plasma membrane due to exaggerated storage in the neuronal cytoplasm (B), in subcellular compartments that are involved in biosynthesis, namely Golgi complex and endoplasmic reticulum (D and E). (From Dumartin et al., 2000).

populations expressing either isotype has been a matter of debate, interpretation of ISH data being subjected to discussion and controversy (Le Moine and Bloch, 1995). We have studied for long such expression and our data using double ISH bring evidence that D1 and D2 are each expressed by a given output neuronal population (Le Moine et al., 1990; 1991; Le Moine and Bloch 1995; 1996). GABA/SP/Dynorphin neuron express D1R, GABA/Enkephalins neurons express D2R. In the ventral striatum, each of these two neuronal population coexpresses D3 (Le Moine and Bloch 1996; Ridray et al. 1998); acetyl- choline interneurons express both D2 and D5 (Figure 5). Such data help to understand anatomical and cellular basis of drugs that interact with dopamine receptors and help to target drugs that may act in brain with more pharmacological and anatomical precisions. Dopamine denervation alone, similar to the one observed in Parkinson's disease does not substantially modify the pattern of dopamine receptor gene expression in the striatum (Hirsch, 2000). In contrast, the association of dopamine denervation and L-DOPA treatment (ie conditions of Parkinson's disease treatment) provokes uprise of D3 in neurons in the 

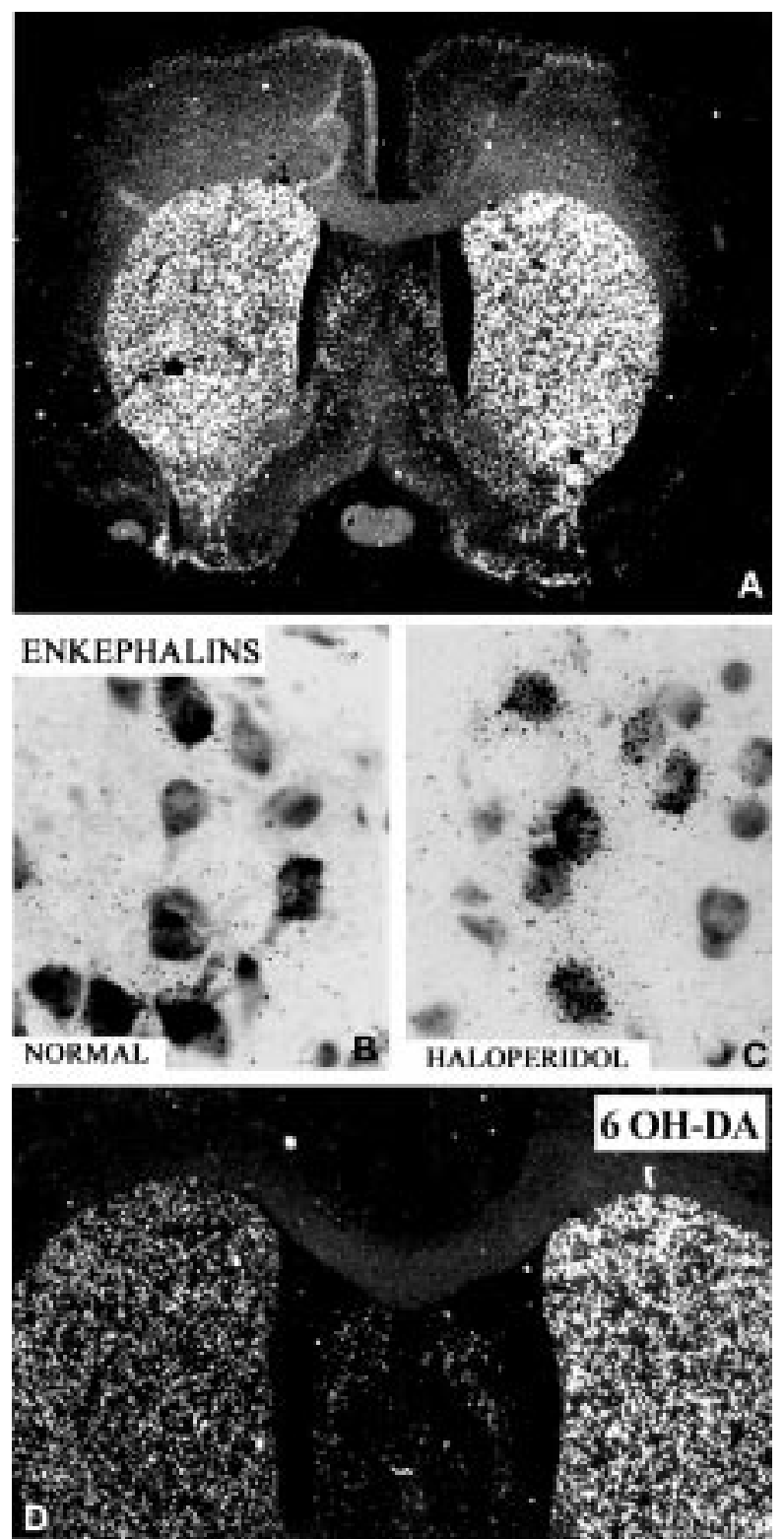

Fig. 8 - Influence of dopamine environment on enkephalin gene expression in the rat striatum. A shows detection of enkephalin mRNA by ISH (S35 labelled probe) in normal rat. Numerous neurons are labelled in the striatum. B an C show enkephalin mRNA in normal rat and in rat treated during two weeks by haloperidol (a dopamine antagonist). Messenger RNA abundance, as detected by silver grain after radioautography is increased after haloperidol treatment. (from Normand et al., 1986). D shows enkephalin mRNA detection in the rat forebrain after destruction of dopamine neurons of the right substantia nigra. In absence of dopamine, enkephalin mRNA accumulates in the striatum and the signal is more important on the right side of the brain. dorsal striatum (Bordet et al. 1997; Hirsch et al 2000). The results demonstrate that receptor equipment can be dramatically influenced by specie, and/or neurochemical environment in experimental conditions. Indeed, ISH has also demonstrated that many other neurotransmitter receptors are expressed by striatal neurons, such as receptors for adenosine, acetylcholine or opioid peptides (Bernard et al., 1992; Svenningsson et al., 1998, Georges et al., 2000), not all of them being so far identified (Figure 5). Altogether, these investigations have permitted to associate each striatal neuronal subpopulation with subsets of their neurotransmitter receptors.

Regulation of genic activity by dopamine in striatal neurons

Dopamine environment has been demonstrated to profundly modify the genic activity of striatal neurons in many ways. While the complexity of dopamine action is extreme in this respect, many works associating pharmacological approaches and molecular neuroanatomy have allowed to propose models to understand how this neurotransmitter is involved in striatal functions through regulation of the transcriptional activity of genes coding for GAD and neuropeptides in acute and chronic conditions (Young, et al., 1986; Normand et al. 1988; Gerfen et al., 1990; Le Moine et al., 1997; Gerfen et al., $2000 \mathrm{a}, \mathrm{b}$ ): quantitative ISH proves to be very useful to explore how neurochemical environment influences gene expression in defined neuronal populations with exquisite resolution (Fig. 8). As an example, in rats, dopamine denervation or neuroleptic treatment upregulates enkephalin mRNA and down regulates SP mRNA but has no influence on dynorphin striatal mRNA (Young et al., 1986; Normand et al. 1988; Gerfen et al., 1990). Somatostatin and acetylcholine production are unaffected by denervation. In primates, the situation is more complex but it appears that dopamine denervation upregulates enkephalin mRNA (Gerfen 2000a; Hirsch 2000). On the basis of neurochemical experiments associating dopamine denervation and use of specific D1 and D2 agonists, C. Gerfen proposed a model for dopamine action on neuropeptide 
gene expression depending on neuronal subpopulations (Gerfen et al. 1990; Gerfen 2000a; Gerfen 2000b). Dopamine environment also modifies gene expression for dopamine receptors (Gerfen, 2000a). As indicated previously, dopamine deprivation associated with L-DOPA induces D3 gene expression in all neurons of the dorsal striatum. D1 and D2 mRNA are also regulated though to a lesser extent inside neurons that already express it.

Dopamine environment also influences gene expression for proto-oncogenes such as c-fos and c-jun. Such genes, once activated, encode trancriptional factors that in turn modulate the activity of other genes such as the ones coding for neurotransmitters. Proto-oncogene expression in striatal neurons can be analysed by ISH or IHC. It is a precious indicator to identify the neuronal populations that are activated by changes in their neurochemical environment (Le Moine et al. 1997; Svenningsson et al. 1999; Gerfen et al., 2000a, 2000b). Protooncogene activation helps to map neuronal targets for many drugs such as neuroleptics or dopamine agonists, (cocaine, amphetamines) or opiates (Graybiel et al. 1990; Liu et al. 1994). It also helps to understand what are the neuronal basis for neurotransmitter interactions. As an example, on the basis of such investigations, C. Le Moine and colleagues have proposed a model for cellular basis of adenosine and dopamine interactions on striatal output neurons (Le Moine et al. 1997; Svenningsson et al. 1999).

Altogether, results obtained from fifteen years demonstrate that dopamine environment acts with very complex modes to regulate gene activity for neurotransmitters and receptors; such regulation involves proto-oncogene activation. It illustrates also that drugs interacting with neurotransmission have most generally actions at the gene level, either on a short term or a long term basis.

\section{Regulation by dopamine of the trafficking of dopamine receptors}

Receptors were considered to be synthesized in neuronal cell bodies and targeted to the plasma membrane of the neurones were they became available for interactions with neurotransmitters or related drugs such as agonists or antagonists. Immunoelectron microscopy demonstrated that these receptors were, in most instances, associated with the plasma membrane, either in synaptic or extra synaptic location (Figure 6). From many years, biochemical studies developed "in vitro" in transfected non neuronal cells had demonstrated that under stimulation, receptors undergo complex intracellular trafficking that modulate abundance and availability of these receptors at the cell surface. This includes $G$ protein coupled receptors that under acute stimulation undergo rapid plasma membrane depletion and internalisation in endosomes, associated with complex phosphorylationdephosphorylation that ultimately lead to receptor desensitisation and recycling (Koenig and Edwardson 1997). In 1996, Mantyh and coworkers demonstrated that in brain, acute stimulation of SP receptors by substance P indeed provokes SP receptors internalisation in neuronal cytoplasm in endosomes, within minutes after stimulation and a subsequent receptor return at the membrane (Mantyh et al. 1995a; Mantyh et al. 1995b). Similarly, in striatal neurons, D1 dopamine receptors internalises in the cytoplasm within minutes after direct stimulation by agonist or after amphetamine injection that each stimulates dopamine release (Dumartin et al. 1998) (Figure 6). This leads to dramatic and rapid dopamine receptor plasma membrane depletion. Detailed electron microscopic studies demonstrated that these receptors are stored in endosomes after internalisation, but also, in certain instances, are targeted to multivesicular bodies for degradation (Bernard et al., 1998) (Figure 6). Cessation of drug treatment leads to receptor recovery at the plasma membrane. D2 $\mathrm{R}$ also internalises after acute stimulation. Chronic stimulation also leads to dramatic redistribution of D1R in striatal neurons. There is a dramatic membrane depletion associated with exaggerated storage of D1R in the endoplasmic reticulum and Golgi complex. Such changes are reversible under restauration of normal dopamine level (Figure 7), (Dumartin et al. 2000). In Parkinson's diseased brain, D1R also undergoes abnormal subcellular localisation involving internalisation in the cytoplasm (Muriel et al. 1999). In the striatum, glutamate stimulation provokes redistribution of D1R that 
are initially located in axons and translocated to the plasma membrane (Scott et al. 2002). Anaysis of trafficking of muscarinic receptors in striatal neurons under direct or indirect acetylcholine stimulation in acute and chronic conditions also demonstrates complex intraneuronal trafficking that is dependant of the nature of the neuronal subpopulation and of the condition of stimulation; Bernard et al., 1998, 1999; Liste et al., 2002). Altogether these results demonstrate that the neurochemical environment contributes to regulate $\mathrm{G}$ protein coupled receptor abundance at the cell surface by regulating its intraneuronal compartmentalisation in short term or long term situations through intracytoplasmic trafficking involving cell body, dendrites and axons (Bloch et al. 1999). This also suggests that such modifications can have direct influence on neuronal sensitivity to neurotransmitters or related drugs in experimental and pathological conditions.

\section{WHAT IS THE FUTURE FOR MOLECULAR NEUROANATOMY?}

From forty years, molecular anatomy has demonstrated that the histological localisation of molecules involved in neurotransmission helps to understand anatomical and cellular basis for neuronal interactions. It also demonstrates that such interactions are far more sophisticated than previously expected on the basis of initial discoveries on nervous system structure. Molecular anatomy also contributes to demonstrate that such interactions involve dynamic mechanisms at the level of neurotransmitter production, receptor production and subcellular compartmentalisation and regulation of gene transcription that need to be explored at the anatomical, cellular and subcellular level. Many data have established that such regulations largely contribute to influence interneuronal relationships in physiological, experimental and pathological conditions. Such advances already provide important basis for understanding the physiology of neuronal circuits, including those involved in control of motricity, pain, or behavior. Such data also provide important grounds for understanding neurochemical basis of diseases involving neurotransmitters such as schiz- ophrenia, Parkinson's disease, mood disorders and drug addiction (Hirsch et al., 2000; Gerfen et al., 2002; Scott et al. 2002). It will also help to understand actions of drugs in brain, whatever drugs of addiction or molecules interacting with neurotransmission used to cure neurological and neuropsychiatric disorders. Molecular neuroanatomy with available techniques has still important challenges, such as the understanding of alterations in production and localization of neurotransmitters and receptors in neurological and neuropsychiatric disorders in human brain. New techniques will most probably add to the potential of molecular anatomy such as the ones allowing the direct visualisation of neurotransmitter liberation or receptors movements inside neurons.

\section{REFERENCES}

Agnati L.F., Zoli M., Stromberg I., and Fuxe K.: Intercellular communication in the brain: wiring versus volume transmission. Neuroscience 69, 711-26, 1995.

Aubert I., Ghorayeb I., Normand E., and Bloch B.: Phenotypical characterization of the neurons expressing the D1 and D2 dopamine receptors in the monkey striatum. J. Comp. Neuro.1 418, 22-32, 2000.

Barry J., Dubois P., and Poulain P.: LRF producing cells of the mammalian hypothalamus. A fluorescent antibody study. Z. Zellforsch. Mikrosk. Anat. 146, 351-366, 1973.

Beaudet A., Dournaud P., and Boudin H.: Complementarity of radioautographic and immunohistochemical techniques for localizing neuroreceptors at the light and electron microscopy level. Braz. J. Med. Biol. Res. 31, 215-23, 1998.

Bernard V., Gardiol A., Faucheux B., Bloch B., Agid Y., and Hirsch E.C.: Expression of glutamate receptors in the human and rat basal ganglia: effect of the dopaminergic denervation on AMPA receptor gene expression in the striatopallidal complex in Parkinson's disease and rat with 6-OHDA lesion. J. Comp. Neurol. 368, 553-68, 1996.

Bernard V., Laribi O., Levey A.I., and Bloch B.: Subcellular redistribution of $\mathrm{m} 2$ muscarinic acetylcholine receptors in striatal interneurons in vivo after acute cholinergic stimulation. J. Neurosci. 18, 10207-18, 1998.

Bernard V., Levey A.I., and Bloch B.: Regulation of the subcellular distribution of $\mathrm{m} 4$ muscarinic acetylcholine receptors in striatal neurons in vivo by the cholinergic environment: evidence for regulation of cell surface receptors by endogenous and exogenous stimulation. J. Neurosci. 19, 10237-49, 1999.

Bernard V., Normand E., and Bloch B.: Phenotypical characterization of the rat striatal neurons expressing muscarinic receptor genes. J. Neurosci. 12, 3591-600, 1992. 
Bloch B., Baird A., Ling N., and Guillemin R.: Immunohistochemical evidence that growth hormone-releasing factor (GRF) neurons contain an amidated peptide derived from cleavage of the carboxyl-terminal end of the GRF precursor. Endocrinology 118, 156-162, 1986.

Bloch B., Bugnon C., Fellmann D., Lenys D., and Gouget A. Neurons of the rat hypothalamus reactive with antisera against endorphins, acth, msh and B-LPH. Cell. Tissue Res. 204, 1979, 1-15.

Bloch B., Dumartin B., and Bernard V.: In vivo regulation of intraneuronal trafficking of $\mathrm{G}$ protein-coupled receptors for neurotransmitters. Trends Pharmacol. Sci. 20, 315-9, 1999.

Bloch B., Popovici T., Le Guellec D., Normand E., Chouham S., Guitteny A.F., and Bohlen P.: In situ hybridization histochemistry for the analysis of gene expression in the endocrine and central nervous system tissues: a 3-year experience. J. Neurosci. Res. 16, 183-200, 1986.

Bordet R., Ridray S., Carboni S., Diaz J., Sokoloff P., and Schwartz J.C.: Induction of dopamine D3 receptor expression as a mechanism of behavioral sensitization to levodopa. Proc. Natl. Acad. Sci. USA 94, 3363-7, 1997.

Brana C., Caille I., Pellevoisin C., Charron G., Aubert I., Caron M.G., Carles D., Vital C., and Bloch B.: Ontogeny of the striatal neurons expressing the D1 dopamine receptor in humans. J. Comp. Neurol. 370, 23-34, 1996.

Brown J.L., Liu H., Maggio J.E., Vigna S.R., Mantyh P.W., and Basbaum A.I.: Morphological characterization of substance $\mathrm{P}$ receptor-immunoreactive neurons in the rat spinal cord and trigeminal nucleus caudalis. J. Comp. Neurol. 356, 327-44, 1995.

Caille I., Dumartin B., and Bloch B.: Ultrastructural localization of D1 dopamine receptor immunoreactivity in rat striatonigral neurons and its relation with dopaminergic innervation. Brain Res. 730, 17-31, 1996.

Cajal S., and Ramon Y.: Histologie du système nerveux de l'homme et des vertébrés. Maloine Edts, Paris, 1909.

Carlsson A, Falck B, and Hillarp N.: Cellular localization of brain monomamines. Acta Physiol. Scand. 56, 1-27, 1962.

Castel M.N., Morino P., Nylander I., Terenius L., and Hokfelt T.: Differential dopaminergic regulation of the neurotensin striatonigral and striatopallidal pathways in the rat. Eur. J. Pharmacol. 262, 1-10, 1994.

Chabot J.G., Kar S., and Quirion R.: Autoradiographical and immunohistochemical analysis of receptor localization in the central nervous system. Histochem. J. 28, 729-45, 1996.

Coons A.H.: The development of IHC. Ann. NY Acad. Sci. 177, 5-9, 1971.

Costa, M., Furness, J.B., Cuello, A.C., Verhofstad, A.A., Steinbusch, H.W., and Elde, R.P.: Neurons with 5-hydroxytryptamine-like immunoreactivity in the enteric nervous system: their visualization and reactions to drug treatment. Neuroscience 7, 351-63, 1982.
Dumartin B., Caille I., Gonon F., and Bloch B.: Internalization of D1 dopamine receptor in striatal neurons in vivo as evidence of activation by dopamine agonists. J. Neurosci. 18 1650-61, 1998

Dumartin B., Jaber M., Gonon F., Caron M.G., Giros B., and Bloch B.: Dopamine tone regulates D1 receptor trafficking and delivery in striatal neurons in dopamine transporter-deficient mice. Proc. Natl. Acad. Sci. USA 97, 1879-84, 2000.

Falck B., Hillarp N., Thieme G., and Torp A.: Fluorescence of catecholamines and related compounds condensed with formaldehyde. J. Histochem. Cytochem. 10, 348-354, 1962.

Georges F., Normand E., Bloch B., and Le Moine C.: Opioid receptor gene expression in the rat brain during ontogeny, with special reference to the mesostriatal system: an in situ hybridization study. Dev. Brain Res. 109, 187-189, 1998.

Gerfen C.R.: The neostriatal mosaic: multiple levels of compartmental organization. Trends Neurosci. 15, 133-9, 1992a.

Gerfen C.R.: The neostriatal mosaic: multiple levels of compartmental organization in the basal ganglia. Annu. Rev. Neurosci. $15,285-320,1992$ b.

Gerfen C.R.: Dopamine-mediated gene regulation in models of Parkinson's disease. Ann. Neurol. 47, S42-50; discussion S50-2, 2000a

Gerfen C.R.: Molecular effects of dopamine on striatal-projection pathways. Trends Neurosci 23, S64-70, 2000 b.

Gerfen C.R., Engber T.M., Mahan L.C., Susel Z., Chase T.N., Monsma F.J.Jr., and Sibley D.R.: D1 and D2 dopamine receptor-regulated gene expression of striatonigral and striatopallidal neurons. Science 250, 1429-32, 1990.

Georges F., Normand E., Bloch B., and Le Moine C. Opioid receptor gene expression in the rat brain during ontogeny, with special reference to the mesostriatal system: an in situ hybridization study. Dev. Brain Res. 109, 187-189, 1998.

Graybiel A.M., Moratalla R., and Robertson H.A.: Amphetamine and cocaine induce drug-specific activation of the $\mathrm{c}$ fos gene in striosome-matrix compartments and limbic subdivisions of the striatum. Proc. Natl. Acad. Sci. USA 87, 6912-6, 1990 .

Guitteny A.F., Fouque B., Mougin C., Teoule R., and Bloch B.: Histological detection of messenger RNAs with biotinylated synthetic oligonucleotide probes. J. Histochem. Cytochem. 36, 563-71, 1988

Gurevich E.V., and Joyce J.N.: Distribution of dopamine D3 receptor expressing neurons in the human forebrain: comparison with D2 receptor expressing neurons. Neuropsychopharmacology 20, 60-80, 1999.

Hirsch E.C.: Nigrostriatal system plasticity in Parkinson's disease: effect of dopaminergic denervation and treatment. Ann. Neurol. 47, S115-20; discussion S120-1, 2000.

Hokfelt T.: Neuropeptides in perspective: the last ten years Neuron. 7, 867-79, 1991. 
Hokfelt T., Fuxe K., and Goldstein M.: Applications of IHC to studies on monoamine cell systems with special reference to nervous tissues. Ann. NY Acad. Sci. 254, 407-32, 1975.

Hokfelt T., Johansson O., Fuxe K., Elde R., Goldstein M., Park D., Efendic S., Luft R., Fraser H., and Jeffcoate S.: Hypothalamic dopamine neurons and hypothalamic peptides. Adv. Biochem. Psychopharmacol. 16, 99-108, 1977.

Hokfelt T., Johansson O., and Goldstein M.: Chemical anatomy of the brain. Science 225, 1326-34, 1984

Hokfelt T., Johansson O., Ljungdahl A., Lundberg J.M., and Schultzberg M.: Peptidergic neurones. Nature 284, 515-21, 1980a.

Hokfelt T., Rehfeld J. F., Skirboll L., Ivemark B., Goldstein M., and Markey K.: Evidence for coexistence of dopamine and CCK in meso-limbic neurones. Nature 285, 476-8, 1980b.

Hokfelt T., Zhang X., and Wiesenfeld-Hallin Z.: Messenger plasticity in primary sensory neurons following axotomy and its functional implications. Trends Neurosci. 17, 22-30, 1994.

Jansson A., Goldstein M., Tinner B., Zoli M., MeadorWoodruff J.H., Lew J.Y., Levey A.I., Watson S., Agnati, L.F., and Fuxe K.: On the distribution patterns of D1, D2 tyrosine hydroxylase and dopamine transporter immunoreactivities in the ventral striatum of the rat. Neuroscience 89 , 473-89, 1999.

Kawaguchi Y., Wilson C.J., Augood S.J., and Emson P.C. Striatal interneurones: chemical, physiological and morphological characterization. Trends Neurosci. 18, 527-35, 1995.

Koenig, J.A., and Edwardson J.M.: Endocytosis and recycling of G protein-coupled receptors. Trends Pharmacol. Sci. 18 276-87, 1997

Kohler C., and Steinbusch H.: Identification of serotonin and non-serotonin-containing neurons of the mid-brain raphe projecting to the entorhinal area and the hippocampal formation. A combined immunohistochemical and fluorescent retrograde tracing study in the rat brain. Neuroscience 7 $951-75,1982$

Le Moine C., Bernard V., and Bloch B.: Quantitative in situ hybridization using radioactive probes in the study of gene expression in heterocellular systems. Methods Mol. Biol. 33, 301-11, 1994

Le Moine C., and Bloch B.: D1 and D2 dopamine receptor gene expression in the rat striatum: sensitive cRNA probe demonstrate prominent segregation of D1 and D2 mRNAs in distinct neuronal populations of the dorsal and ventral striatum. J. Comp. Neurol. 355, 418-26, 1995.

Le Moine C., and Bloch B.: Expression of the D3 dopamine receptor in peptidergic neurons of the nucleus accumbens: comparison with the D1 and D2 dopamine receptors. Neuroscience 73, 131-43, 1996

Le Moine C., Normand E., and Bloch B.: Phenotypical characterization of the rat striatal neurons expressing the D1 dopamine receptor gene. Proc. Natl. Acad. Sci. USA 88, 4205-9, 1991.
Le Moine C., Normand E., and Bloch B.: Use of non-radioactive probes for mRNA detection by in situ hybridization: interests and applications in the central nervous system. Cell Mol. Biol. (Noisy-le-grand) 41, 917-23, 1995.

Le Moine C., Normand E., Guitteny A.F., Fouque B., Teoule R., and Bloch B.: Dopamine receptor gene expression by enkephalin neurons in rat forebrain. Proc. Natl. Acad. Sci. USA 87, 230-4, 1990

Le Moine C., Svenningsson P., Fredholm B.B., and Bloch $\mathrm{B}$.: Dopamine-adenosine interactions in the striatum and the globus pallidus: inhibition of striatopallidal neurons through either D2 or A2A receptors enhances D1 receptormediated effects on c-fos expression. J. Neurosci. 17, 803848, 1997.

Liste I., Bernard V., and Bloch B. Acute and chronic acetylcholinesterase inhibition regulates in vivo the localization and abundance of muscarinic receptors $\mathrm{m} 2$ and $\mathrm{m} 4$ at the cell surface and in the cytoplasm of striatal neurons. Mol. Cell. Neurosci., sous presse.

Liu J., Nickolenko J., and Sharp F.R.: Morphine induces c-fos and junB in striatum and nucleus accumbens via D1 and $\mathrm{N}$ methyl-D-aspartate receptors. Proc. Natl. Acad. Sci. USA 91, $8537-41,1994$

Mantyh P.W., Allen C.J., Ghilardi J.R., Rogers S.D., Mantyh C.R., Liu H., Basbaum A.I., Vigna S.R., and Maggio J.E.: Rapid endocytosis of a $\mathrm{G}$ protein-coupled receptor: substance $\mathrm{P}$ evoked internalization of its receptor in the rat striatum in vivo. Proc. Natl. Acad. Sci. USA 92, 2622-6, 1995a.

Mantyh P.W., DeMaster E., Malhotra A., Ghilardi J.R. Rogers S.D., Mantyh C.R., Liu H., Basbaum A.I., Vigna S.R., Maggio J.E., et al.: Receptor endocytosis and dendrite reshaping in spinal neurons after somatosensory stimulation. Science 268, 1629-32, 1995b.

Muriel M.P., Bernard V., Levey A.I., Laribi O., Abrous D.N., Agid Y., Bloch B., and Hirsch E.C.: Levodopa induces a cytoplasmic localization of D1 dopamine receptors in striatal neurons in Parkinson's disease. Ann. Neurol. 46, 103-11, 1999.

Normand E., Popovici T., Fellmann D., and Bloch B. Anatomical study of enkephalin gene expression in the rat forebrain following haloperidol treatment. Neurosci. Lett. 83, 232-236, 1987.

Normand E., and Bloch B.: Simultaneous detection of two messenger RNAs in the central nervous system: a simple two-step in situ hybridization procedure using a combination of radioactive and non-radioactive probes. J. Histochem. Cytochem. 39, 1575-8, 1991.

Normand E., Popovici T., Onteniente B., Fellmann D., PiatierTonneau D., Auffray C., and Bloch B.: Dopaminergic neurons of the substantia nigra modulate preproenkephalin A gene expression in rat striatal neurons. Brain Res. 439, 39-46, 1988.

Ridray S., Griffon N., Mignon V., Souil E., Carboni S., Diaz J., Schwartz J.C., and Sokoloff P.: Coexpression of dopamine D1 and D3 receptors in islands of Calleja and shell of nucleus accumbens of the rat: opposite and synergistic functional interactions. Eur. J. Neurosci. 10, 1676-86, 1998. 
Schiffmann S.N., and Vanderhaeghen J.J.: Lesion of the nigrostriatal pathway induces cholecystokinin messenger RNA expression in the rat striatum. An in situ hybridization histochemistry study. Neuroscience 50, 551-7, 1992.

Schiffmann S.N., and Vanderhaeghen J.J.: Caffeine regulates neurotensin and cholecystokinin messenger RNA expression in the rat striatum. Neuroscience 54, 681-9, 1993.

Scott L., Kruse M.S., Forssberg H., Brismar H., Greengard P., and Aperia A.: Selective up-regulation of dopamine D1 receptors in dendritic spines by NMDA receptor activation. Proc. Natl. Acad. Sci. USA 99, 1661-4, 2002.

Smith A.D., and Bolam J.P.: The neural network of the basal ganglia as revealed by the study of synaptic connections of identified neurones. Trends Neurosci. 13, 259-65, 1990.

Svenningsson P., Le Moine C., Aubert I., Burbaud P., Fredholm B., and Bloch B. Cellular distribution of adenosine A2A receptor mRNA in the primate striatum. J. Comp. Neurol. 399, 229-240, 1998.
Svenningsson P., Fourreau L., Bloch B., Fredholm B.B., Gonon F., and Le Moine C.: Opposite tonic modulation of dopamine and adenosine on c-fos gene expression in striatopallidal neurons. Neuroscience 89, 827-37, 1999.

Suzuki M., Hurd Y.L., Sokoloff P., Schwartz J.C., and Sedvall G.: D3 dopamine receptor mRNA is widely expressed in the human brain. Brain Res. 779, 58-74, 1998.

Trembleau A., Roche D., and Calas A.: Combination of nonradioactive and radioactive in situ hybridization with IHC: a new method allowing the simultaneous detection of two mRNAs and one antigen in the same brain tissue section. $\mathbf{J}$. Histochem. Cytochem. 41, 489-98, 1993.

Young W.S.3 ${ }^{\text {rd }}$, Bonner T.I., and Brann M.R.: Mesencephalic dopamine neurons regulate the expression of neuropeptide mRNAs in the rat forebrain. Proc. Natl. Acad. Sci. USA 83 9827-31, 1986.

Young W.S.: In situ hybridisation Histochemistry. In "Handobook of Chemical Neuroanatomy, Vol. 8; Blorklund, A. Hokfelt, T. Wouterlood, F. Van den Pol Edts. 481-506, 1990 